\title{
Past, present, and future perspectives on the governance of waste household appliances in China: A 20-year review based on CiteSpace analysis
}

\author{
Huiying $\mathrm{YU}^{1, *}$ \\ ${ }^{1}$ Business Administration Department, Nanjing University of Aeronautics and Astronautics, Nanjing, 211106, China
}

\begin{abstract}
This study offers a systematic review of the research on the treatment of waste household appliances in China in the past 20 years. A total of 1123 related articles were selected from the CNKI database from 1998 to 2020 to sort out the hot spots, evolution and frontier trends. The results show that: (1) In the past 20 years, the research on waste household appliances in China has followed the development path of "society-technology-human", gradually evolving from the macro level to the micro level, and the research in the field of waste household appliances governance has begun to take shape. (2) With the increasing enrichment of research methods and the continuous expansion of research ideas, the research topic breaks through the boundaries of single theory and discipline, and reverse logistics, closed-loop supply chain, recycling behavior, recycling and dismantling technology, etc. have become research hotspots. (3) From the initial study of the management experience of developed countries to the study of recycling management with Chinese characteristics, China's "Internet + recycling" model is ahead of the international level and has become the latest research hotspot.
\end{abstract}

\section{Introduction}

With the shortening of the life cycle of electrical products, electronic household appliance have begun to enter the product decline stage, the global elimination rate has been increasing and its number has reached a new peak. China's televisions, refrigerators and other end-of-life product have exceeded 11 million tons, with an average annual growth rate of $20 \%$. Therefore, the governance of waste household appliances is an urgent environmental, economic and social problem to be solved in China. At present, the literature review on the governance of waste household appliances in Chinese academic circles stays at the level of introduction and comment, and there is a gap in the discussion based on the analysis of measurement. Chinese scholars have published a large number of literature in domestic and foreign journals on this issue, but Chinese literature is the main type of discussion, and CNKI is the main research and publication field. Therefore, this paper takes the relevant literature of the CNKI database as the source, and uses CiteSpace to sort out and analyze the research status of waste household appliances in China, so as to provide a panoramic view for researchers in this field.

\section{Basic survey of research on waste household appliances}

\subsection{Data sources and research methods}

Taking "waste household appliances" as the search subject word, it is searched in the CNKI. The search interval was determined from 1998 to December 2020 based on the earliest appearance and development time of the research on waste household appliances. In this paper, newspapers and other invalid literatures are excluded when selecting data, and the final sample size is 1123, including 809 journal papers, 293 master's degree theses, and 21 doctoral theses. The method of bibliometrics and visualization software (CiteSpace), are used to analyze the data records, including literature statistical analysis, research institution analysis, keyword co-occurrence and cluster analysis.

\subsection{Annual volume of papers analysis and analysis of research institutions}

The number of literatures over the years can reflect the research trend to a certain extent. The research on waste household appliances is an important part of e-waste management and environmental governance in recent years. China began to pay attention to the problem of waste household appliances in 1998. The number of

\footnotetext{
* Corresponding author: 1209012391@qq.com 
publications reached a peak in 2007, and then declined and showed a steady development trend. The main reason can be attributed to the successive promulgation and implementation of the "Regulations on the Recycling of Waste Household Appliances and Electronic Products" and the "Technical Policy for Pollution Prevention and Control of Waste Household Appliances and Electronic Products". In 2006, the National Development and Reform Commission has begun to organize, coordinate, and supervise the governance of waste household appliances. This has aroused the attention of scholars. In the second half of the "13th Five-Year Plan" period, the Chinese government implemented the "Circular Development Leading Plan", which was manifested in the academic field as an increase in the number of research on waste household appliances. Under the background of the country vigorously promoting the development of circular economy, the governance of waste household appliances will still be a key research field in the future.

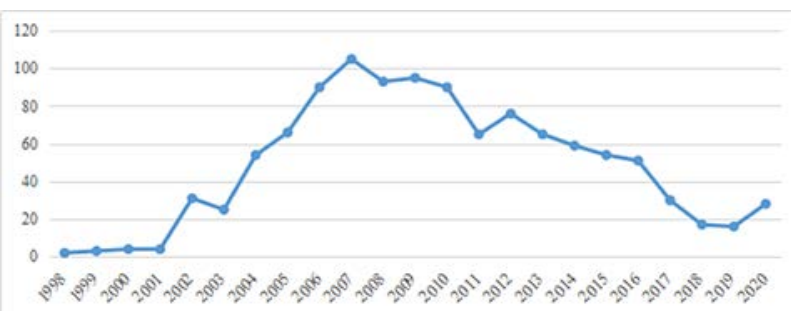

Fig. 1. The trend map of the number of research documents on waste household appliances in China from 1998 to 2020

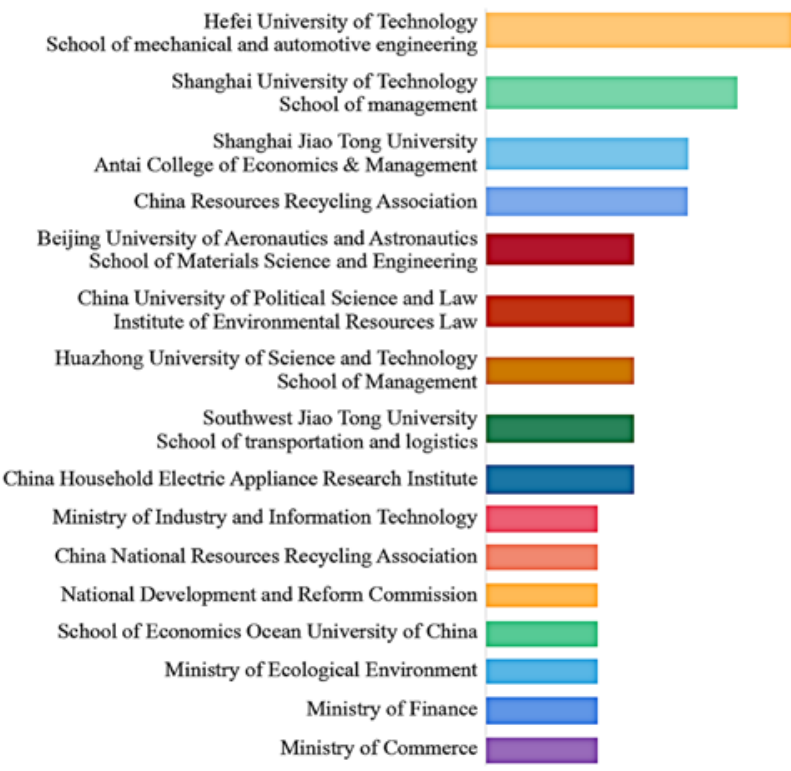

Fig. 2. Research institutes in the number of papers published

According to Figure 2, from the perspective of the macroscopic literature publishing organizations, the hot areas are the economically developed regions in the east, such as Beijing, Shanghai, Qingdao, while the western region has not yet discussed the issue of the governance of waste household appliances in depth. From the perspective of the departments of the micro literature publishing organizations, interdisciplinary has become the main research mode. Literature publications are mainly concentrated in the school of economics and management, school of transportation and logistics, school of mechanical and automotive engineering, involving multiple professional directions such as business management, logistics management, and mechanical engineering. At the same time, it can be seen that the state attaches great importance to this issue, involving the Development and Reform Commission, the Ministry of Industry and Information Technology, the Ministry of Environmental Protection and other departments. However, the core research groups with relatively stable and high academic level have not yet been formed, and more scholars from different directions are needed in this field to solve realistic research problems through interdisciplinary and "industryuniversity-research cooperation".

\subsection{Analysis of the research context of waste household appliances}

\subsubsection{Keyword co-occurrence clustering analysis}

Keyword clustering can accurately reflect the research hotspots, as shown in figure 3. There are both overlap and differences in keyword clustering in the research field of waste household appliances, and the research content and direction present a state of multi-disciplinary intersection. In the visual analysis, the centrality can reflect the role of the node in the whole network, and the higher the value is, the more important the node is. In the literature related to the governance of waste household appliances, in addition to waste household appliances (0.37) and waste household appliance recycling (0.23), recycling (0.17), reverse logistics (0.15), consumers $(0.1)$, recycling system $(0.07)$, closed-loop supply chain (0.03), recycling behavior (0.02), recycling and dismantling technology (0.02), and legislation (0.01) have relatively large centrality values. These keywords show the research hotspots from a certain point of view.

Table 1. Keywords with their frequencies in the governance of waste household appliances

\begin{tabular}{c|c|c}
\hline Keyword & Frequency & Centrality \\
\hline Waste household appliances & 323 & 0.37 \\
\hline Waste household appliance recycling & 106 & 0.23 \\
\hline Recycling & 78 & 0.17 \\
\hline Reverse logistics & 160 & 0.15 \\
\hline Circular economy & 83 & 0.15 \\
\hline Consumer & 26 & 0.1 \\
\hline Recycling system & 36 & 0.07 \\
\hline Closed-loop supply chain & 18 & 0.03 \\
\hline Reverse supply chain & 10 & 0.02 \\
\hline Recycling behavior & 9 & 0.02 \\
\hline Recycling technology & 8 & 0.02 \\
\hline Legislation & 18 & 0.01 \\
\hline
\end{tabular}




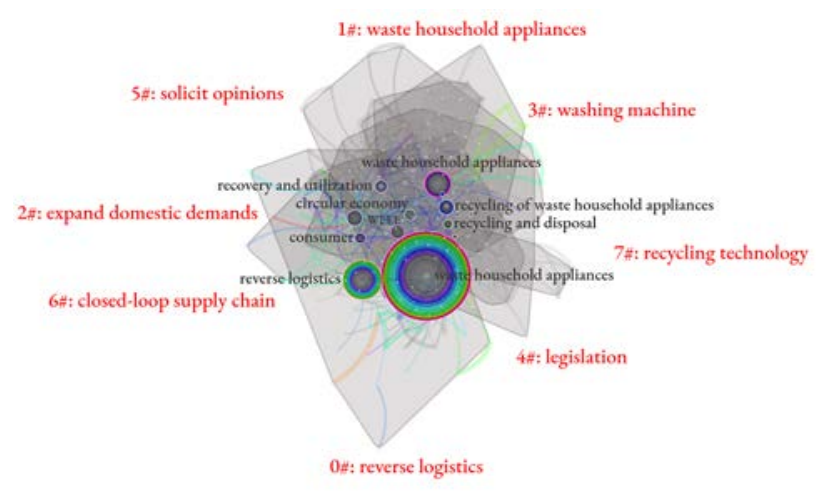

Fig. 3. Keyword co-occurrence clustering diagram

\subsubsection{Keyword evolution trend}

Burst terms recognition is to identify the words with the highest rate of change in a certain period of time to reveal the phased research hotspots and evolution trends. According to Table 1, it can be seen that "waste household appliances" first appeared in 2002 and became a hot spot, and later co-occurred with keywords such as "circular economy", "legislation", "producer responsibility". Chinese scholars begin to conduct indepth research based on the perspective of social system such as policy and legislation. "Recycling Channel" appeared as a research hotspot for the first time in 2007, co-appeared with "network planning", and gradually became a research hotspot with key words such as "closed-loop supply chain", "reverse supply chain", "recycling mode" and "recycling and dismantling". "Influencing factors" first appeared in 2013, and the importance of consumers' behavior has been paid attention to. Chinese scholars began to pay attention to the technical factors of the governance of waste household appliances. The "Internet + recycling" model appeared in 2016 and has become a research hotspot. Based on the above analysis, it can be seen that the research on waste household appliances in China follows the development path of "society-technology-people", and gradually evolves from macro to micro level.

\begin{tabular}{|c|c|c|c|c|}
\hline \multicolumn{5}{|c|}{ op 17 Keywords with the Strongest Citation Bursts } \\
\hline Keywords & Strength & Begin & End & $1998-2020$ \\
\hline aste hous & 5463 & 2002 & 2005 & ----- \\
\hline legislation & 157 & 04 & 2006 & ------ \\
\hline producer responsibility & 3616 & 2004 & 2006 & ---------------- \\
\hline circular e & 52 & 2005 & 2006 & 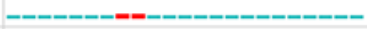 \\
\hline recycling & 2733 & 2007 & 2009 & 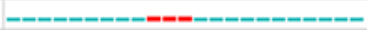 \\
\hline cycling as $r a t h e$ & 1 & 09 & 10 & 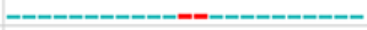 \\
\hline ade & 8 & 09 & 2 & ----------------- \\
\hline networ & 1 & 11 & 2013 & ---- \\
\hline closed-loop supply chain & 43 & 2012 & 2018 & 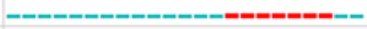 \\
\hline reverse sup & 6202 & 12 & 2016 & 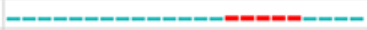 \\
\hline recycling: & 2 & 13 & 2016 & 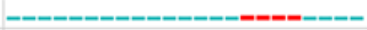 \\
\hline re & & 13 & 2018 & 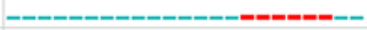 \\
\hline influencing factor & 3668 & 2013 & 2015 & 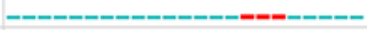 \\
\hline recycling system & 1 & 13 & 2016 & 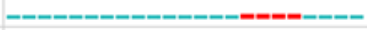 \\
\hline recyclir & & & 2020 & 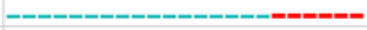 \\
\hline & & 5 & 2020 & 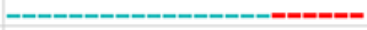 \\
\hline "internet + recycling" & 3.1257 & 2016 & 2020 & 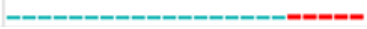 \\
\hline
\end{tabular}

Fig. 4. Top 17 citations with strong citation burst

\section{Analysis on the research field of the governance of waste household appliances}

Based on the statistical analysis of the papers on the governance of waste household appliances, the cooccurrence map of keywords, clustering and analysis of burst terms, through the systematic reading of the relevant literature, according to the time sequence of the research on waste household appliances in our country, it is concluded that the governance of waste household appliances in China is mainly concentrated in the following three main areas.

\subsection{Research on policies and regulations}

Since 2003, in order to reduce the environmental problems caused by waste household appliances, and achieve the goal of sustainable development, the state has intensively promulgated laws and policies related to the recycling of waste household appliances. Under the guidance of national principles and policies, scholars carry out research from three aspects: legislation, law enforcement and learning from the advanced experience of developed countries. Some scholars expounded the relevant legal situation of waste household appliances in developed countries (European Union, Japan, United States). Based on the current situation of legislation on recycling and disposal in our country, the studies analyze the existing problems in national legislation and the future countermeasures. At the same time, another group of scholars focused on the market-oriented operation and management of waste household appliance disposal funds in China, and advocated drawing lessons from the mature experience and practices of Japan, such as legislative system and responsibility-sharing mechanism. In 2007, the "producer responsibility" was included as an important system in the draft of the Circular Economy Law. Scholars believe that in order to extend producer responsibility in our country, it is necessary to rationally design its basic links and establish a sound relevant guarantee system. In 2010, related keywords such as "scrapping, recycling, dismantling" have become the focus of the legislative work of the State Council. Chen introduced in detail the technical status of the recycling, dismantling and reuse of scrapped automobiles at household and abroad, and proposed our country's recycling technical standards and measures [1]. In July 2005, the State Council issued some opinions on speeding up the development of circular economy, and the work of circular economy in China was started in an all-round way. Xie preliminarily discussed the theoretical and policy issues of developing circular economy in China, which can be used as a reference for academia and practical work departments [2]. In July 2009, government promulgated the "Implementation Measures for the Exchange of Old Home Appliances". Kong aimed at the problems in the implementation of the policy of trade-in for household appliances, drawing lessons from international experience, the paper puts forward the industrial sustainable development model 
suitable for China's national conditions and the specific countermeasures for the construction of the model [3].

\subsection{Research on the recycling mode and recycling system}

The recycling mode and recycling system of waste household appliances are mainly carried out around reverse logistics and closed-loop supply chain. Reverse logistics is a complex and coordinated process with manufacturers, consumers and recyclers, and perfect reverse logistics is a powerful guarantee to support the recycling of waste household appliances. The research of Chinese scholars on reverse logistics system mainly focuses on three aspects: decision-making research, cost research and system research. In their research, Zeng and others use the cost-benefit mathematical model to build a reverse logistics system based on the Internet and optimize it [4]. In order to improve the overall operational efficiency of the reverse logistics system, $\mathrm{Li}$ combines location, routing and inventory problems and develops a two-stage heuristic algorithm based on mixed integer programming model [5]. The closed-loop supply chain involves a series of changes from the strategic level to the operational level, and is not a simple algebraic sum of "forward + reverse". The research of closed-loop supply chain in China mainly involves three aspects: decision-making model, network design and supply chain coordination. Lu used Stackelberg game theory to explore the optimal decision-making of the remanufacturing closed-loop supply chain in different situations through simulation [6]. Based on scenario analysis, aiming at the uncertainty of product demand and recovery rate of waste household appliances, Gao constructed a closed-loop supply chain network design model and verified its effectiveness [7]. Under the background of government rewards and punishments for producers' carbon emissions, Wang constructs centralized, decentralized and decentralized decisionmaking models introducing improved revenue-sharing contracts, respectively. It is proved that the improvement of revenue-sharing contracts is conducive to closed-loop supply chain coordination [8]. In May 2016, the state emphasized the need to promote the new model of "Internet + recycling". Scholars begin to discuss the new opportunities and challenges facing China's resource recovery under this mode by analyzing the process and characteristics of the "Internet + recycling" model.

\subsection{Research on influencing factors of recycling behavior}

According to the different starting point of recycling, recycling behavior can be divided into industrial recycling and consumer recycling. The research on the influencing factors of consumers' recycling behavior refers to taking consumers as the main body of the study to explore the influencing factors of recycling willingness in different situations and how these factors affect the driving mechanism of recycling behavior. The recycling decision is a complex process, which is affected by internal psychological factors and external situational factors at the same time.

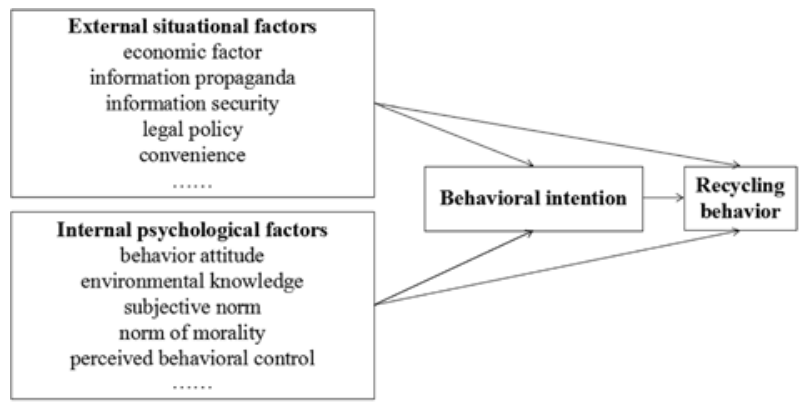

Fig. 5. Integrated framework for research on recycling behavior of waste household appliances

Internal psychological factors: This field studies the influence of psychological variables on behavior based on behavioral theory. Most of the research is to introduce new internal factors on the basis of planned behavior theory and rational behavior theory to build a more reasonable and specific recycling behavior model. Internal psychological variables mainly include attitude, beliefs, values, subjective norms, perceptual behavior control and moral sense and so on. Lan has proved through empirical research that the behavior intention of waste household appliances disposal is positively related to behavior attitude, subjective norms, economic motivation and service motivation, negatively related to behavior control, and has nothing to do with environmental knowledge [9]. Some scholars proved that the influence of environmental knowledge, perceived behavior control, behavior attitude and subjective norms on behavior intention increased in turn.

External situational factors: It refers to the objective environment faced by consumers in the choice of recycling behavior, including economic factors, information publicity, convenience of recycling channels, information security, laws and policies and so on. Contextual factors are of great significance to the study of recycling behavior, mainly through regulation, mediation and direct effects. The existing studies mainly focus on the intermediary effect, while the direct effect research is relatively few. In the study of recycling of waste household appliances, $\mathrm{Yu}$ proved that environmental knowledge and public opinion propaganda and other contextual factors have a moderating effect on recycling behavior [10]. Although studies focusing on external situational factors have found several influencing rules on recycling behavior, there are few studies focusing on the interaction of internal psychological factors and external situational factors on recycling behavior. In addition, studies on spatial attributes and third parties on the Internet enrich external situational studies, such as Chen, who have an insight into the spatial differences and distribution of residents' recycling behavior from the perspective of spatial attributes. It provides new ideas and methods for the practice of e-waste recycling [11]. 


\section{Conclusions}

By depicting the knowledge graph of domestic research on waste household appliances from 1998 to 2020, the conclusions are as follows: (1) In recent years, the research on waste household appliances in China follows the development path of "society-technology-people", and gradually evolves from macro to micro level. The research in the field of waste household appliances management is beginning to take shape. (2) The research content continues to be refined and deepened, new theories and technologies continue to break through, and research methods, content and angles are increasingly enriched. Recycling, reverse logistics, closed-loop supply chains, recycling behavior, recycling and dismantling technologies, etc. have all become research hotspots. (3) From the initial study of the management experience of developed countries to the study of recycling management methods with Chinese characteristics, China's "Internet + recycling" model is ahead of the international level and has become the latest research hotspot.

However, there are still some weaknesses in the current research. China is still faced with unreasonable policies of the existing collection, transportation and disposal system, inadequate government supervision of disposal enterprises, and insufficient attention and guidance to the development of disposal technology. The public's willingness to recycle is not strong. Therefore, future research can proceed from reality, respectively from the social system (public public service system, government regulatory policy), technological system (recycling model, recycling system) and participants (manufacturers, recyclers, consumers) and other aspects of in-depth research to promote technological and theoretical innovation. The details are as follows: (1) Strengthen the research on the construction and implementation of laws and policies, establish a guiding mechanism, improve the incentive mechanism, strengthen the restraint mechanism, improve the guarantee mechanism, and form a comprehensive legal system supported by environmental, health, and safety laws. Establish the necessary infrastructure and strategic planning research for the recycling and management of waste household appliances, and realize the organic combination of online delivery and offline recycling. (2) Adhere to technological innovation, pay attention to the promotion strategy research of "Internet + recycling" mode, strive to promote the innovation of recycling mode, and establish a sound and perfect recycling system. Expand the scope of application of big data and information systems, extend to the entire process of the production and recycling of waste household appliances, and form a full life cycle management process. (3) Tripartite collaborative research of recyclers, consumers, and manufacturers. The effect of recovery is largely determined by the interaction and cooperation of the three parties in the whole process of recycling. China has a special cultural background, and the pro-environmental attitudes of Chinese consumers that respect "Tao law of nature" and "The harmony of man and nature" are very different from the low recycling behavior. It is necessary to make an in-depth study on the psychological mechanism behind the recycling of consumers' waste household appliances, and explore the internal and external attributes of their behavior. Future research can focus on consumer behavior and intervention strategies, establish effective behavior models, formulate intervention strategies and explore trust transmission pathways based on environmental behavior theories, such as ABC theory, normative activation theory, valuebelief-norm theory, regulatory orientation theory.

\section{References}

1. Si C. Recycling, dismantling and reuse of end-oflife automobiles. J. ATM 8, 6-9 (2007)

2. Zhenhua X. Thoughts on the Theory and Policy of Circular Economy. J. CEA 5, 11-17 (2005)

3. Lingfeng K. Home appliance trade-in and home appliance enterprises implement a circular economy strategy. J. EPCE 30, 13-15 (2010)

4. Youxin Z. Optimization of e-waste reverse logistics system based on the Internet of Things. J. EE 31, 112-117 (2015)

5. Zhuoni L. Research on residents' willingness to participate in e-waste recycling under the background of "Internet+". J. ERG 9, 125-128 (2019)

6. Zhengnan L. Research on Decision-making of Remanufacturing Closed-loop Supply Chain Considering Recycling Quality. J. EE 36, 194-199 (2020)

7. Hongju G. The closed-loop supply chain network design considering the risk of carbon emission reductio. J. IEM 22, 8-14 (2017)

8. Daoping W. Dynamic Optimization of Supply Chain Cooperative Emission Reduction and Promotion under Government Subsidies. J. SM 30, 14-27 (2021)

9. Ying L. Analysis and Empirical Research on the Influencing Factors of Users' Disposal Behavior Intentions of Waste Household Appliances. J. FC 28, 65-70 (2009)

10. Fumao Y. The Influence of Situational Factors on the Recycling Behavior of Urban Residents' Waste Home Appliance. J. EE 10, 137-141 (2012)

11. Lanfang C. Research on Recycling Behavior and Spatial Attributes of Urban Residents. J. TEI 18, 4652 ( 2020) 